\title{
Intelligence Quotient at the Age of Six years of Iranian Children with Congenital Hypothyroidism
}

\author{
Khaled Rahmani, Shahin Yarahmadi, Koorosh Etemad, Yadollah Mehrabi, Nasrin Aghang, Ahmad \\ KOOSHA AND HAMID SOORI \\ From Department of Endocrinology and Metabolism, Ministry of Health, Tehran, Iran. \\ Correspondence to: Dr Hamid Soori, Safety Promotion and Injury Prevention Research Center, School of Public Health, \\ Shahid Beheshti University of Medical Sciences, Tehran,Iran.hsoori@yahoo.com. \\ Received: July 27, 2016; Initial Review: November 05, 2016; Accepted: September 01, 2017.
}

Objective: To evaluate the success rate of the National newborn screening program in maintenance of intelligent quotient (IQ) of children with congenital hypothyroidism in Iran.

Design: Retrospective cohort study.

Methods: The IQ scores, in three subsets of verbal, non verbal (Performance) and full scale IQ, of 240 children diagnosed with Transient congenital hypothyroidism (TCH) and Permanent congenital hypothyroidism $(\mathrm{PCH})$, from 5 provinces in 5 different geographical areas of Iran, were measured at the age of 6 years using revised Wechsler pre school and primary scale of intelligence and compared with 240 healthy children. We used independent sample t test and two-way ANOVA for data analysis.

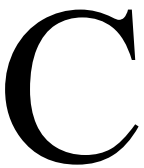
ongenital hypothyroidism $(\mathrm{CH})$ is considered as one of the most important preventable causes of mental retardation in children [1]. The incidence of $\mathrm{CH}$ is different among neonates of various countries of the world and ranges from 1:2000 to 1:4000 [2-6], the incidence of $\mathrm{CH}$ in different areas of Iran is reported to vary from 1:400 to $1: 1000[7,8]$.

In Iran, a National program of neonate screening was established from 2004-2005 [9]. In this program, thyroidstimulating hormone (TSH) is measured as a primary test, and positive tests are confirmed by serum thyroxine (T4). By the end of 2015, over 9 million neonates were screened and over 10 thousand children were diagnosed with $\mathrm{CH}$ and treated with levothyroxine (L-Thyroxine).

The evaluation of this mass screening program, particularly from the view of maintaining the IQ of children with $\mathrm{CH}$ at the national level has been done $[10,11]$, but there have been no systematic long-term follow-up studies for evaluation of intervention/treatment outcomes among hypothyroid children diagnosed by the nationwide newborn screening program in Iran. This study was done to assess the IQ of hypothyroid children
Results: Mean of verbal, performance, and full scale IQ scores were lower in the $\mathrm{CH}$ cases (permanent and transient) than the control group. Most of the IQ differences in two studied groups related to the $\mathrm{PCH}$ cases $(P=0.005)$. Mean difference of IQs between children in the two groups in Yazd province (center of Iran) was higher than other provinces, and they also had significantly lower IQ than their control (healthy) children $(P=0.001)$. No treated child had $\mathrm{IQ}<70$.

Conclusion: Although mean IQs of $\mathrm{CH}$ children was lower than their controls, IQ of all treated $\mathrm{CH}$ cases were close to the healthy children.

Keywords: Management, Neonatal screening, Outcome. diagnosed by national program of $\mathrm{CH}$ screening at age of 6 years, compared with healthy children in Iran.

Accompanying Editorial: Pages 113-14

\section{MethodS}

This was a retrospective cohort study conducted in five provinces in different geographical areas of Iran. A total of 480 children in two study groups, including 240 children with $\mathrm{CH}$ and 240 healthy children were investigated in this comparative study. We first specified our samples based on mean difference sample size formula, then we modified our selected samples based on the number of children diagnosed with $\mathrm{CH}$ in all five studied provinces.

After calculation of primary sample size $(N=314$ children), we modified it based on all diagnosed hypothyroid children in a year ( $N=1000$ children) and final sample size in each group was obtained as 240.

Children with $\mathrm{CH}$ were cases diagnosed by National newborn screening program and treated with levothyroxine, six years before this study. These cases were selected by systematic random sampling from National newborn screening program registry in Iran. For 
each case, we took one healthy child as the control and matched it with $\mathrm{CH}$ child based on age, sex and place of birth. For age-matching, we selected a child that was born at \pm 3 month intervals of $\mathrm{CH}$ cases. The ethical approval of this research was given by Shahid Beheshti University of Medical Sciences ethics committee.

Iran has 31 provinces; all 31 provinces of the country were divided into 5 regions, viz. North (including 7 provinces), South (including 5 provinces), East (including 5 provinces), West (including 8 provinces) and Center (including 6 provinces); then we randomly selected one province in each region consisting of Mazandaran, Khuzestan, Razavi Khorasan, Kurdistan and Yazd, respectively. The number of samples in each province was determined based on the number of children diagnosed with $\mathrm{CH}$ or by probability proportional to size (PPS) sampling method. Sampling in each of five selected provinces was conducted by systematic sampling method using the list of identified hypothyroid children. The intelligence quotient (IQ) scores, were measured at age six years using revised Wechsler Pre school and Primary Scale of Intelligence (WPPSI-R) and compared with the control group.

All analyses were conducted using STATA version 14 using independent-sample t-test and two-way ANOVA. We also checked two main assumptions of independentsamples t-test and ANOVA including normality of IQ as dependent variable and homogeneity of variances by Kolmogorov-Smirnov test and Levene's test, respectively.

\section{RESUltS}

A total of $240 \mathrm{CH}$ cases and 240 healthy (control) children were enrolled $(49.2 \%$ males). One hundred thirty one $(54.6 \%)$ of $\mathrm{CH}$ cases had transient congenital hypothyroidism (TCH) and 109 cases $(45.4 \%)$ had permanent congenital hypothyroidism (PCH). Demographic characteristics of studied children are presented in Table $\mathbf{I}$. The number of children enrolled in each of the $\mathrm{CH}$ and control group from the five sites was 69 (Khuzestan), 51 (Razavi khorasan), 50 (Kurdistan), 40 (Yazd), and 30 (Mazandaram).
Mean (SD) of IQ for $\mathrm{CH}$ cases and healthy children were 101.1 (13.7) and 104.5 (14.5), respectively $(P=0.01)$. This difference was also seen in two main components of IQ (verbal and non-verbal IQ).

Table II shows the relationship between mean IQ and other categorical variables (province of residence, sex, and type of hypothyroidism) in two study groups. The mean difference for verbal, non-verbal and full-scale IQs between $\mathrm{CH}$ and control children were 3.2, 3.1 and 3.4, respectively. There were significant differences between province of residence and the mean IQ of children in both two groups $(P<0.05)$. The results of HSD test for mean verbal IQ showed that there are statistical significant differences between Kurdistan and Yazd $(P<0.001)$, Yazd and Khuzestan $(P<0.001)$, Razavi Khorasan and Khuzestan $(P<0.001)$ in control groups and also there were statistical significant differences between Kurdistan and Yazd $(P=0.002)$, Yazd and Khuzestan $(P<0.001)$, Razavi Khorasan and Khuzestan $(P=0.01)$ in $\mathrm{CH}$ cases. The results of HSD test for mean non-verbal IQ was only statistical significant between Khuzestan and Mazandaran provinces $(P=0.01)$. Although HSD test results for mean difference of Full scale IQ showed significant difference between Kurdistan and Yazd $(P=0.02)$, Yazd and Khuzestan $(P<0.001)$, Razavi Khorasan and Khuzestan $(P=0.02)$, Khuzestan and Mazandran $(P<0.001)$ in control groups but the mean difference of Full scale IQ was only significant between Khuzestan and Mazandran in $\mathrm{CH}$ cases $(P=0.04)$.

There were no statistical significant differences between IQ and type of $\mathrm{CH}$. There were statistically significant differences in mean of full scale IQ between PCH cases and their controls $(P=0.005)$, and also for verbal IQ $(P=0.01)$ and non-verbal (Performance) IQ $(P=0.02)$.

\section{Discussion}

In this study, we evaluated the success rate of early detection and timely $\mathrm{T} 4$ supplementation in children with $\mathrm{CH}$ via measuring the IQ of treated cases at age of 6 years and comparing with healthy children as their control group. Our results demonstrated that the mean (SD) IQ of

TABLE I Demographic Characteristics of the Study Participants $(n=480)$

\begin{tabular}{llrr}
\hline Characteristic & CH cases $(n=240)$, & Control group $(n=240)$ & Total \\
\hline Gestational age, no. $(\%)$ & & & $17(7.1)$ \\
Preterm (<37 weeks) & $24(10)$ & $219(91.2)$ & $41(8.5)$ \\
Full term (37-42 weeks) & $209(87.1)$ & $6(0.3)$ & $6(0.35)$ \\
Age (y), mean (SD) & $6(0.4)$ & $3294.1(553.2)$ & $3246.34(569.4)$ \\
Weight (g) at birth, mean (SD) & $3198.5(605.1)$ & &
\end{tabular}


TABLE II Results of IQ Assessment IN THE Study Population $(N=480)$

\begin{tabular}{|c|c|c|c|c|c|c|}
\hline & \multicolumn{2}{|c|}{ Verbal IQ } & \multicolumn{2}{|c|}{ Non verbal IQ } & \multicolumn{2}{|c|}{ Full scale IQ } \\
\hline & CH cases & $\begin{array}{l}\text { Controls } \\
\text { (Performance) IQ }\end{array}$ & CHcases & Controls & CH cases & Controls \\
\hline \multicolumn{7}{|l|}{ Province } \\
\hline Khuzestan & $94.7(17.6)$ & $96.5(16.6)$ & $99.5(16.1)$ & $100.3(15.7)$ & $97.4(15.7)$ & $98.5(16.4)$ \\
\hline Razavi Khorasan & $103.3(13.9)^{*}$ & $109.2(13.6)^{*}$ & $99.7(13.1)$ & $101.9(14.1)$ & $101.5(12.3)$ & $106.1(12.9)$ \\
\hline Kurdistan & $98.4(12.4)$ & $99.5(14.4)$ & $103.9(13.2)$ & $104.9(10.9)$ & $101.3(12.4)$ & $102.3(11.7)$ \\
\hline Yazd & $110.4(11.8)^{\#}$ & $116.9(10.6)^{\#}$ & $95.5(11.3)$ & $103.8(9.3)$ & $\$ 103.4(10.9)$ & $\$ 111.2(9.4)$ \\
\hline Mazandaran & $103.2(17.3)$ & $104.3(18.2)$ & $103.8(18.2)$ & $110.4(20.6)$ & $105.7(15.2)$ & $110.1(16.3)$ \\
\hline Total & $101.0(15.8)$ & $104.2(16.5)$ & $100.3(14.7)$ & $103.4(14.5)$ & $101.1^{\#}(13.7)$ & $104.5^{\#}(14.5)$ \\
\hline \multicolumn{7}{|l|}{ Type of CH } \\
\hline $\mathrm{TCH}$ & 100.6 (15.9) & $101.9(16.0)$ & $101.1(14.7)$ & $102.8(13.7)$ & $101.1(13.9)$ & $102.6(13.9)$ \\
\hline $\mathrm{PCH}$ & $101.6(15.6)^{\#}$ & $107.0(16.8)^{\#}$ & $99.4(14.6)$ & $104.1(15.5)$ & $101.2(13.6)$ & 106.7 (14.9) \\
\hline \multicolumn{7}{|l|}{ Gender } \\
\hline Boys & 102.8 (14.9) & $105.8(15.7)$ & $102.4(14.1)$ & $103.9(13.3)$ & 102.9 (13.3) & $105.6(13.9)$ \\
\hline Girls & $99.3(16.5)$ & $102.7(17.2)$ & ${ }^{\# 98.3 ~(14.9)}$ & ${ }^{\#} 102.9(15.7)$ & *99.3 (13.9) & ${ }^{*} 103.4(15.1)$ \\
\hline
\end{tabular}

$\mathrm{CH}$ cases [101.1 (13.7)] after adjustment for age, sex and socioeconomic status (SES) was significantly lower than their controls [104.5 (14.5)]. Although, the results indicated lower mean IQ scores of $\mathrm{CH}$ cases comparing their controls, the success rate of $\mathrm{CH}$ detection and treatment at first weeks after birth is evaluated high because mean IQs of all cases at age 6 years were within the normal range.

In this study, we showed that there are no significant differences between $\mathrm{CH}$ patients and their controls in 6 years after treatment. Our results are consistent with many previous studies $[12,13]$. Previous studies indicate that severity of $\mathrm{CH}$ (defined by initial thyroxine at the moment of diagnosis and by skeletal maturation) is most important individual risk factor for neuropsychologic development in patients with $\mathrm{CH}$ [14]. In this study, we showed that the type of hypothyroidism (transient or permanent) is a main risk factor in IQ deficit, and despite timely detection and treatment of $\mathrm{CH}$ cases in our program, there are more IQ deficit in children with permanent rather than transient $\mathrm{CH}$. The difference between the IQs of cases and controls in $\mathrm{PCH}$ was 4 times more than TCH cases. In a previous study, it was demonstrated that there is no associations between Transient hypo-thyroxinemia of prematurity (THoP) and neuro-developmental outcome at age 19 years [15]. Our results are also consistent with the study of cognitive and motor outcome of early treatment of 82 Dutch $\mathrm{CH}$ patients [16], where patients with severe $\mathrm{CH}$ had lower verbal, performance, and full-scale IQs than the normative population, whereas IQ scores of patients with moderate and mild $\mathrm{CH}$ were comparable to those of the normative population [16].

In addition to the genetic factors, age, sex and SES are considered most important confounders when we compare the difference between the IQ of $\mathrm{CH}$ cases and healthy children [17-19]. In this study, we approximately eliminate the effect of these potential confounders with individually matching of $\mathrm{CH}$ subjects and their controls based on age, sex and SES during the primary sampling process. We used valid and widely accepted IQ test. Comparing the IQs of patients with $\mathrm{CH}$ in two separate $\mathrm{CH}$ types ( $\mathrm{TCH}$ and $\mathrm{PCH}$ ) and subjects sampling from different areas of the country were another strengths of current study.

Although our findings highlight the success of Iran National program of neonatal screening for detection and treatment of $\mathrm{CH}$ cases, the IQ of hypothyroid children was lower than healthy children and more emphasis should be placed on the strengthening the surveillance system, particularly timely visit by physician and systematic controlling of serum thyroid hormones level to assure thyroxine compensation in children with $\mathrm{CH}$. We strongly suggest systematic surveillance of children with $\mathrm{CH}$ during first 6 years of life, particularly in $\mathrm{PCH}$ cases which may ensure better control of congenital hypothyroidism, and prevent its adverse effects. 


\section{What is AlREady KnOWn?}

- Children with congenital hypothyroidism have improvement in IQ after timely detection and treatment.

What this Study Adds?

- Neonates identified with congenital hypothyroidism at birth by neonatal screening had mean IQ lower than unaffected children at 6 years of age but none had a sub-normal $(<70)$ IQ.

Acknowledgements: This work was supported by Department of Endocrinology and Metabolism, Ministry of Health, Tehran, Iran in collaboration with Department of Epidemiology at Shahid Beheshti University of Medical Sciences.

Contributors: HS, SY, KR, NA: study concept and design. KR, YM: analysis and interpretation of data and drafting the manuscript. KE, AK: drafting the manuscript. All authors approved the final manuscript.

Funding: Department of Endocrinology and Metabolism, Ministry of Health, Tehran, Islamic Republic of Iran. Competing interests: None stated.

\section{REFERENCES}

1. Schoenmakers N, Alatzoglou KS, Chatterjee VK, Dattani MT. Recent advances in central congenital hypothyroidism. J Endocrinol. 2015;227:R51-R71.

2. Deladoey J, Ruel J, Giguere Y, Van Vliet G. Is the incidence of congenital hypothyroidism really increasing? A 20-year retrospective population-based study in Quebec. J Clin Endocrinol Metab. 2011;96:2422-9.

3. Fan X, Chen S, Qian J, Sooranna S, Luo J, Li C, et al. Incidence and interrelated factors in patients with congenital hypothyroidism as detected by newborn screening in Guangxi, China. Glob Pediatr Health. 2015;2:2333794X14567193.

4. Gu X, Wang Z, Ye J, Han L, Qiu W. Newborn screening in China: phenylketonuria, congenital hypothyroidism and expanded screening. Ann Acad Med Singapore. 2008;37:107-4.

5. Harris KB, Pass KA. Increase in congenital hypothyroidism in New York State and in the United States. Mol Genet Metab. 2007;91:268-77.

6. Skordis N, Toumba M, Savva SC, Erakleous E, Topouzi M, Vogazianos $\mathrm{M}$, et al. High prevalence of congenital hypothyroidism in the Greek Cypriot population: results of the neonatal screening program 1990-2000. J Clin Endocrinol Metab. 2005; 18:453-62.

7. Dorreh F, Chaijan PY, Javaheri J, Zeinalzadeh AH. Epidemiology of congenital hypothyroidism in Markazi Province, Iran. J Clin Res Pediatr Endocrinol. 2014;6:105.

8. Ghasemi M, Hashemipour M, Hovsepian S, Heiydari K, Sajadi A, Hadian R, et al. Prevalence of transient congenital hypothyroidism in central part of Iran. J Res Med Sci. 2013;18:699.

9. Zeinalzadeh AH, Talebi M. Neonatal screening for congenital hypothyroidism in East Azerbaijan, Iran: The first report. J Med Screen. 2012;19:123-6.

10. Hashemipour M, Dehkordi EH, Hovsepian S, Amini M, Hosseiny L. Outcome of congenitally hypothyroid screening program in Isfahan: Iran from prevention to treatment. Int J Prev Med. 2010;1:92.

11. Karamizadeh Z, Saneifard H, Amirhakimi G, Karamifar H, Alavi M. Evaluation of congenital hypothyroidism in Fars province, Iran. Iran J Pediatr. 2012;22:107-12.

12. Albert BB, Heather N, Derraik JG, Cutfield WS, Wouldes $\mathrm{T}$, Tregurtha $\mathrm{S}$, et al. Neurodevelopmental and body composition outcomes in children with congenital hypothyroidism treated with high-dose initial replacement and close monitoring. J Clin Endocrinol Metab. 2013;98:3663-70.

13. Aleksander P, Blankenstein O, Gruters A, Krude H. No difference in cognitive development of young adults and adolescents affected by congenital hypothyroidism compared to their sibling controls despite high dose Lthyroxine treatment. 2014. ESPE Abstracts (2014) 82 PD-2-1-589.

14. Derksen-Lubsen G, Verkerk P. Neuropsychologic development in early treated congenital hypothyroidism: Analysis of literature data. Pediatr Res. 1996;39:561-6.

15. Hollanders JJ, Israëls J, van der Pal SM, Verkerk PH, Rotteveel J, Finken MJ. No association between transient hypothyroxinemia of prematurity and neurodevelopmental outcome in young adulthood. J Clin Endocrinol Metab. 2015;100:4648-53.

16. Kempers MJ, van der Sluijs Veer L, Nijhuis-van der Sanden RW, Lanting CI, Kooistra L, Wiedijk BM, et al. Neonatal screening for congenital hypothyroidism in the Netherlands: Cognitive and motor outcome at 10 years of age. J Clin Endocrinol Metab. 2007;92:919-24.

17. Rabbiosi S, Vigone MC, Cortinovis F, Zamproni I, Fugazzola L, Persani L, et al. Congenital hypothyroidism with eutopic thyroid gland: analysis of clinical and biochemical features at diagnosis and after re-evaluation. J Clin Endocrinol Metab. 2013;98:1395-402.

18. Samadi A, Skocic J, Rovet JF. Children born to women treated for hypothyroidism during pregnancy show abnormal corpus callosum development. Thyroid. 2015;25:494-502.

19. Willoughby KA, McAndrews MP, Rovet J. Effects of early thyroid hormone deficiency on children's autobiographical memory performance. $J$ Int Neuropsychol Soc. 2013;19:419-29. 